\title{
Bimetallic metal organic frameworks with precisely positioned metal centers for efficient $\mathrm{H}_{2}$ storage $\uparrow$
}

\author{
Daeok Kim, ${ }^{a}$ Kyung Seob Song, ${ }^{b}$ Onur Buyukcakir, ${ }^{a}$ Taner Yildirim ${ }^{* c}$ and \\ Ali Coskun $\star b$
}

\begin{abstract}
We demonstrated that the ratio and position of two different metal ions, $\mathrm{Pd}$ and $\mathrm{Cu}$, can be precisely controlled within MOFs through predesigned metal clusters. These MOF structures incorporating $\mathrm{Pd}-\mathrm{Cu}$ paddle wheel units were synthesised simply by reacting $\mathrm{Pd}-\mathrm{Cu}$ acetate metal clusters and tritopic organic linkers at room temperature. Pd-Cu open metal sites were found to be uniformly distributed throughout the MOFs with a ca. 1:1 ratio. The incorporation of Pd into the MOF structure also led to enhanced affinity towards $\mathrm{H}_{2}$ with $Q_{\mathrm{st}}$ values up to $8.9 \mathrm{~kJ} \mathrm{~mol}^{-1}$.
\end{abstract}

Metal-organic frameworks (MOFs) are crystalline porous materials composed of periodic and successive binding of either metal ions or metal oxide clusters with organic linkers. ${ }^{1,2}$ The combinations of metals and organic linkers have already led to a great number of functional porous structures with specifically tailored functions towards gas storage \& separation,,$^{3-6}$ catalysis, ${ }^{7-9}$ bioapplications, ${ }^{10,11}$ sensors, ${ }^{12-14}$ and so on. ${ }^{15,16}$

Recently, MOFs have also been explored as supports for metal and metal oxide nanoparticles to impart new functions such as enhanced gas affinity. ${ }^{17-19}$ Among all the transition metals, Pd has been of considerable interest due to its versatile use in $\mathrm{H}_{2}$ storage. ${ }^{20-23}$ As a pioneering result in this particular area, Kaskel et al. had successfully infiltrated Pd nanoparticles into MOF-5 and achieved enhancement in $\mathrm{H}_{2}$ storage. ${ }^{20}$ Similarly, Suh and coworkers also reported enhanced hydrogen uptake capacities at $77 \mathrm{~K}$ and room temperature owing to the presence of Pd nanoparticles located in the pores of a redox-active $\mathrm{MOF}^{21}$ Latroche et al. demonstrated the incorporation of Pd nanoparticles $(\sim 2.0 \mathrm{~nm})$ within the pores of the MIL-100(Al), compared to the pristine MOF. ${ }^{22}$ This result was explained by the

${ }^{a}$ Graduate School of EEWS, Korea Advanced Institute of Science and Technology (KAIST), 373-1 Guesong Dong, Daejeon, 305-701, Republic of Korea

${ }^{b}$ Department of Chemistry, University of Fribourg, Fribourg 1700, Switzerland. E-mail: ali.coskun@unifr.ch

${ }^{c}$ NIST Center for Neutron Research, National Institute of Standards and Technology, Gaithersburg, Maryland 20899-6102, USA. E-mail: taner@nist.gov

$\dagger$ Electronic supplementary information (ESI) available: Materials, synthesis method, XRD, XPS, gas adsorption result and so on. See DOI: 10.1039/c8cc04661a spillover mechanism in which $\mathrm{H}_{2}$ dissociates at the surface of the Pd nanoparticles and the in situ formed atomic hydrogens diffuse into the pores of MOF. Despite these encouraging results, however, the $\mathrm{Pd} / \mathrm{MOF}$ composites still present important challenges such as the decrease in pore volume and surface area due to the pore blocking by Pd nanoparticles along with their inhomogeneous dispersion and aggregation within MOFs.

Recently, Doonan and coworkers have elegantly reported on the synthesis of $\mathrm{Pd} / \mathrm{Zn}, \mathrm{Pd} / \mathrm{Cu}$, and $\mathrm{Pd} / \mathrm{Ni}$ metal organic polyhedras using bimetallic paddle wheel acetates, thus demonstrating the possibility of using bimetallic clusters as pre-designed secondary building units for the synthesis of bimetallic porous materials. ${ }^{24}$ Along this direction, Serre et al. have also demonstrated the usage of a multi-metal acetic acid complex as a precursor for the synthesis of multi-metal MOF structures. ${ }^{25}$ We note that the immobilization of Pd single atoms in the form of open metal sites (OMSs) within the metal clusters of MOFs can pave the way to realize superior $\mathrm{H}_{2}$ storage materials by offering high $\mathrm{Pd}$ loadings and their homogeneous distribution while preserving high surface area and pore volume. These materials could also enable precise investigation of the guest-Pd interaction both experimentally and computationally by taking advantage of highly crystalline and well-defined MOF structure. The incorporation of precisely positioned Pd-OMSs into the MOFs, however, still remains highly challenging. Here, we report on the synthesis of MOFs with surface areas up to $1494 \mathrm{~m}^{2} \mathrm{~g}^{-1}$ possessing $\mathrm{Pd}-\mathrm{Cu}$ paddle wheel units by simply reacting $\mathrm{PdCu}(\mathrm{AcO})_{4} \mathrm{H}_{2} \mathrm{O}$ with tritopic organic linkers at room temperature (Fig. 1). The resulting MOFs were found to possess nearly $1: 1$ metal ratio $(\mathrm{Pd}: \mathrm{Cu})$ with precisely controlled positions by using the predesigned metal clusters. The incorporation of Pd single atoms in the form of OMSs led to an enhanced affinity towards $\mathrm{H}_{2}$ leading to the $Q_{\text {st }}$ values up to $8.9 \mathrm{~kJ} \mathrm{~mol}^{-1}$.

The synthesis of $\mathrm{PdCu}(\mathrm{AcO})_{4} \mathrm{H}_{2} \mathrm{O}$ was achieved via the dissolution of $\mathrm{Pd}_{3}(\mathrm{AcO})_{6}$ and $\mathrm{Cu}(\mathrm{AcO})_{2} \cdot 2 \mathrm{H}_{2} \mathrm{O}$ in a mixture of acetic acid/ $\mathrm{H}_{2} \mathrm{O}$ at $85{ }^{\circ} \mathrm{C}$ for $3 \mathrm{~h}$, followed by recrystallization at $6{ }^{\circ} \mathrm{C}$ for 3 days. The resulting complex, $\left\{\mathrm{PdCu}(\mathrm{AcO})_{4} \mathrm{H}_{2} \mathrm{O}(\mathrm{AcO})_{2}\right\}_{n}$, formed a superstructure, in which $\mathrm{PdCu}(\mathrm{AcO})_{4} \mathrm{H}_{2} \mathrm{O}$ paddle 


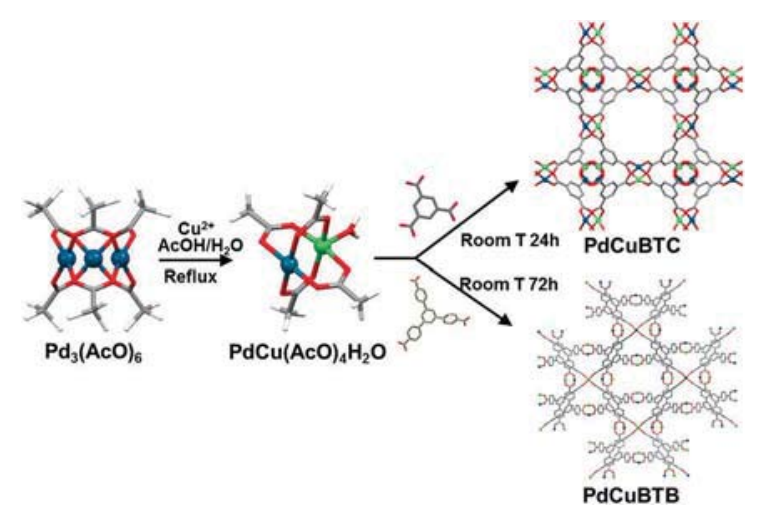

Fig. 1 Synthetic strategy for the preparation of bimetallic MOFs incorporating pre-designed $\mathrm{Pd}-\mathrm{Cu}$ paddle wheel units with precisely controlled metal positions and ratios.

wheel units were linked through hydrogen bonding interactions between coordinated water molecules located on the $\mathrm{Cu}$ sites and excess acetic acid molecules. ${ }^{26}$ The powder X-ray diffraction (XRD) and Fourier transform infrared (FT-IR) spectra of the $\mathrm{Pd}-\mathrm{Cu}$ acetate were in a good agreement with the earlier report (Fig. 1 and Fig. S1, ESI $\dagger$ ), thus confirming its successful formation. We would like to note that the impurities such as Pd nanoparticles formed during the synthesis of $\mathrm{Pd}_{3}(\mathrm{AcO})_{6}$ should be excluded through recrystallization prior to its use to prevent the incorporation of Pd nanoparticles into the resulting MOFs. Two different $\mathrm{PdCu}$ MOFs possessing similar structures to those of $\mathrm{Cu}_{3} \mathrm{BTC}_{2}$ (MOF-199, HKUST-1) ${ }^{27}$ and $\mathrm{Cu}_{3} \mathrm{BTB}_{2}$ (MOF-14) ${ }^{28}$ were obtained by simply mixing $\mathrm{PdCu}(\mathrm{AcO})_{4} \mathrm{H}_{2} \mathrm{O}$ and organic linkers, which are benzene-1,3,5-tricarboxylic acid (BTC) and 1,3,5-tris(4carboxyphenyl)benzene (BTB) in the solvent mixture of DMF/ $\mathrm{EtOH} / \mathrm{H}_{2} \mathrm{O}$ at room temperature. Detailed synthesis procedure is described in the ESI. $\dagger$ The XRD and FT-IR spectra of both PdCuBTC and PdCuBTB matched well with their $\mathrm{Cu}$ analogues, MOF- $199^{27}$ and MOF-14, ${ }^{28}$ respectively (Fig. 2 and Fig. S3, ESI $\dagger$ ). The successful synthesis of two different MOFs by simply varying the size of the organic linker points to the versatile usage of $\mathrm{PdCu}(\mathrm{AcO})_{4} \mathrm{H}_{2} \mathrm{O}$ for the synthesis of various MOFs incorporating $\mathrm{Pd}-\mathrm{Cu}$ paddle wheel units.

In order to observe the morphology of bimetallic MOFs, we have performed scanning electron microscopy (SEM) analyses. SEM images of the PdCuBTC and PdCuBTB showed the formation of crystalline particles (Fig. 3 and Fig. S2, ESI $\dagger$ ). PdCuBTC revealed much smaller particle sizes $(<100 \mathrm{~nm})$ compared to PdCuBTB
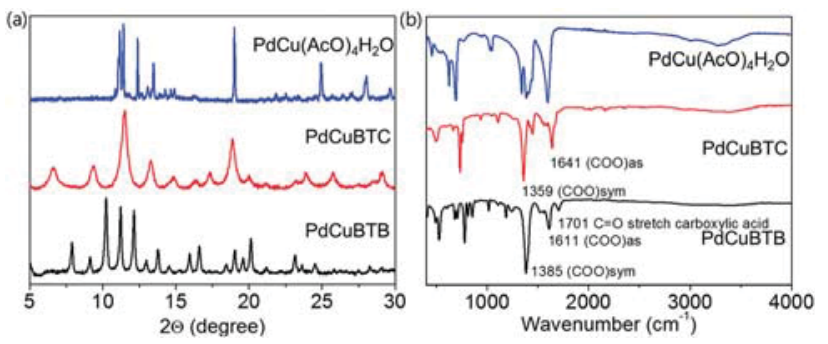

Fig. 2 (a) XRD and (b) FT-IR spectra of $\mathrm{PdCu}(\mathrm{AcO}){ }_{4} \mathrm{H}_{2} \mathrm{O}$ complex and assynthesized PdCu MOFs, namely PdCuBTC and PdCuBTB.

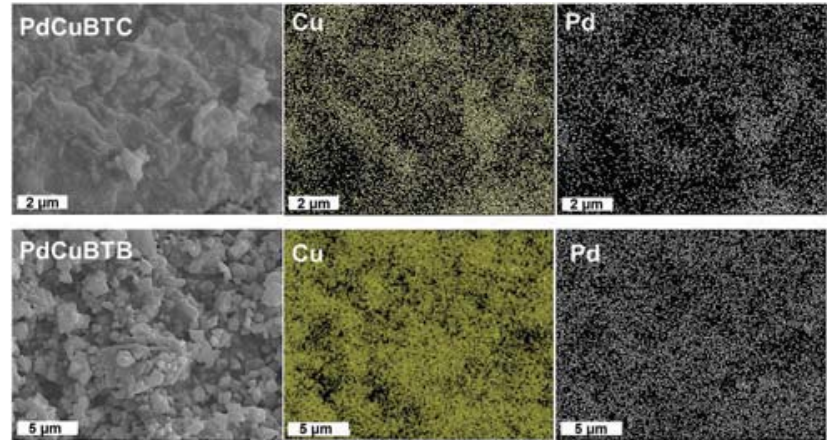

Fig. 3 Energy dispersive spectroscopy (EDS) mapping of PdCuBTC (top) and PdCuBTB (bottom) crystals synthesized by using pre-designed $\mathrm{PdCu}(\mathrm{AcO})_{4} \mathrm{H}_{2} \mathrm{O}$ and organic linkers.

( $\sim 300 \mathrm{~nm})$, which is attributed to the high and low solubility of BTC and BTB linkers in the reaction solvents, respectively. Noticeably the smaller particle size of PdCuBTC resulted in the broadening of XRD peaks compared to that of $\mathrm{Cu}_{3} \mathrm{BTC}_{2}$ (Fig. S3, ESI $\dagger$ ). Also, we attribute the lack of morphology control to the stirring applied during the synthesis. Energy dispersive spectroscopy (EDS) mapping of $\mathrm{Cu}$ and Pd ions of PdCuBTC and PdCuBTB crystals showed homogeneous distribution of both $\mathrm{Pd}$ and $\mathrm{Cu}$, thus confirming the successful incorporation of Pd and $\mathrm{Cu}$ OMSs into the MOF structures. Notably, the important aspect of this approach is that the ratio $\mathrm{Pd}$ and $\mathrm{Cu}$ in $\mathrm{PdCu}(\mathrm{AcO})_{4} \mathrm{H}_{2} \mathrm{O}$ was maintained in the final MOF structures, thus allowing strict control over the metal ratios and positions. The ratios of $\mathrm{Pd}$ and $\mathrm{Cu}$ in $\mathrm{PdCu}(\mathrm{AcO})_{4} \mathrm{H}_{2} \mathrm{O}$ and $\mathrm{PdCu}$ MOFs were analysed via X-ray photoelectron spectroscopy analysis. $\mathrm{PdCu}(\mathrm{AcO})_{4} \mathrm{H}_{2} \mathrm{O}$ showed the $\mathrm{Pd} / \mathrm{Cu}$ molar composition of 50.3/49.7, thus confirming the successful formation of $\mathrm{Pd}-\mathrm{Cu}$ paddle wheel unit. In addition, we also observed $\mathrm{Pd} / \mathrm{Cu}$ molar ratios of 50.1/49.9 and 53.5/46.5 for the PdCuBTC and PdCuBTB, respectively, also an indication for the successful incorporation of $\mathrm{Pd}-\mathrm{Cu}$ paddle wheel units into the resulting MOF structures. Also, inductively coupled plasma atomic emission spectroscopy (ICP-AES) and EDS analysis revealed nearly equimolar composition of Pd and $\mathrm{Cu}$ in both MOFs, thus confirming the successful incorporation of $\mathrm{Pd}-\mathrm{Cu}$ paddle wheel units into the resulting MOFs (Tables S1 and S2, ESI $\dagger$ ).

During the synthesis of PdCu MOFs, we observed immediate formation of a dark-green precipitate when the transparent solutions of $\mathrm{PdCu}(\mathrm{AcO})_{4} \mathrm{H}_{2} \mathrm{O}$ and organic linkers were mixed, which eventually became light-green over the course of the reaction ( 1 and 3 days for PdCuBTC and PdCuBTB, respectively). The understanding of this observation can elucidate the reason for the retention of metal ratio during the MOF synthesis. Accordingly, we have investigated structural changes during the synthesis of MOFs using XRD (Fig. S4a, ESI $\dagger$ ). XRD analysis of dark-green powder revealed new crystalline peaks different from those of $\mathrm{PdCu}(\mathrm{AcO}){ }_{4} \mathrm{H}_{2} \mathrm{O}$, indicating the formation of an intermediate phase. After stirring for 3 days, we observed the diffraction patterns corresponding to PdCuBTB. Importantly, the $2 \Theta$ value of the first peak shifted towards lower angles during the synthesis: $11.1,5.8,4.6^{\circ}$ for $\mathrm{PdCu}(\mathrm{AcO})_{4} \mathrm{H}_{2} \mathrm{O}$, intermediate phase and PdCuBTB, respectively, mainly due to an increase in unit 
cell dimensions. We further investigated the chemical changes using FT-IR (Fig. S4b, ESI $\dagger$ ). $\mathrm{PdCu}(\mathrm{AcO})_{4} \mathrm{H}_{2} \mathrm{O}$ revealed a relatively simple spectrum featuring symmetric and asymmetric stretching vibration modes at 1385 and $1597 \mathrm{~cm}^{-1}$, respectively, which are assigned to the $\mathrm{CH}_{3} \mathrm{COO}^{-}$of the $\mathrm{Pd}-\mathrm{Cu}$ paddle wheel unit. The FT-IR spectrum became more complicated in the intermediate phase, which is relatively similar to that of PdCuBTB. As the intermediate phase formed, the appearance of $\mathrm{C}=\mathrm{O},(\mathrm{COO})_{\mathrm{sym}}$ and $(\mathrm{COO})_{\mathrm{as}}$ vibration peaks at 1688, 1392 and $1601 \mathrm{~cm}^{-1}$ were observed along with a significant change in the entire spectrum, which can be attributed to the ligand exchange from small acetic acid to the bulky BTB linker. Based on these observations, we proposed that the formation of $\mathrm{PdCu}$ MOFs using predesigned bimetallic $\mathrm{Pd}-\mathrm{Cu}$ paddle wheel units involves relatively mild exchange of the acetic acid moieties bonded to the $\mathrm{Pd}-\mathrm{Cu}$ paddle wheel unit with tritopic linkers such as BTC and BTB due to their higher acidity. As this exchange process does not involve the dissociation of metal clusters, it enables the homogeneous distribution of two different metals within the MOF structure with high precision.

The unique bimetallic structure of MOFs also led to peculiar chemical states of metal ions in $\mathrm{Pd}-\mathrm{Cu}$ paddle wheel units. The chemical states of $\mathrm{Pd}$ and $\mathrm{Cu}$ ions in $\mathrm{Pd}_{3}(\mathrm{AcO})_{6}, \mathrm{PdCu}(\mathrm{AcO})_{4} \mathrm{H}_{2} \mathrm{O}$, PdCuBTC and PdCuBTB have been investigated (Fig. S5, ESI $\dagger$ ) using XPS. The $\mathrm{Pd}_{3 \mathrm{~d}}$ XPS spectra of all the samples showed narrow double peaks with binding energies located at 337.1 and $342.5 \mathrm{eV}$ assigned to $\mathrm{Pd}^{2+}$, thus confirming the incorporation of $\mathrm{Pd}$ ions into the paddle wheel units of MOFs. Contrary to the previous report by Fischer et al. ${ }^{29}$ in which PdCuBTC revealed the incorporation of both Pd nanoparticles and $\mathrm{Pd}^{2+}$ into the framework, our approach excluded the formation of Pd nanoparticles, thus enabling the incorporation of single atom Pd OMSs into MOFs. This result is attributed to the mild reaction temperature in our synthesis, room $T$ vs. ca. 120 or $90{ }^{\circ} \mathrm{C}$, prohibiting the formation of Pd or PdO nanoparticles. In order to confirm the absence of Pd or PdO nanoparticles within the MOF crystals, we have analysed the diffraction pattern of PdCuBTB at $2 \Theta$ range from 32 to $42^{\circ}$. Notably, the diffraction peaks originating from (101) plane of PdO and (111) plane of Pd nanoparticles were not observed (Fig. S6, ESI $\dagger$ ), thus verifying our conclusion. Furthermore, $\mathrm{Cu}_{2 \mathrm{P}}$ XPS spectra revealed unique chemical states (Fig. S5, ESI $\dagger$ ). Pd-Cu paddle wheel revealed the combination of $\mathrm{Cu}^{1+}$ and $\mathrm{Cu}^{2+}$. Noticeably, the ratio of $\mathrm{Cu}^{1+}$ and $\mathrm{Cu}^{2+}$ varied depending on the type of organic linkers: $\mathrm{PdCu}(\mathrm{AcO}){ }_{4} \mathrm{H}_{2} \mathrm{O}$ (36.6 : 63.4), PdCuBTC (27.1: 72.9$)$ and PdCuBTB $(57.6: 42.4)$. Notably, these findings are in good agreement with the previously reported examples of $\mathrm{Cu}_{3}(\mathrm{BTC})_{2}$ $\left(\mathrm{H}_{2} \mathrm{O}\right)_{3}$, which also showed the coexistence of $\mathrm{Cu}^{1+}$ and $\mathrm{Cu}^{2+}$ within the paddle wheel units. The reduction of $\mathrm{Cu}^{2+}$ to $\mathrm{Cu}^{1+}$ was attributed to the thermal activation step to remove coordinated solvent molecules occupying axial sites on each $\mathrm{Cu}^{2+}$ ion. This redox phenomenon was suggested to originate from the partial and reversible opening of the paddle wheel units. ${ }^{30-32}$ However, we also do not rule out the possibility of missing organic linkers as the origin of $\mathrm{Cu}^{1+}$ species.

The pore characteristics of PdCuBTC and PdCuBTB were investigated by $\mathrm{Ar}$ adsorption-desorption isotherms measured at $87 \mathrm{~K}$ (Fig. 4a). Both PdCuBTC and PdCuBTB revealed predominantly
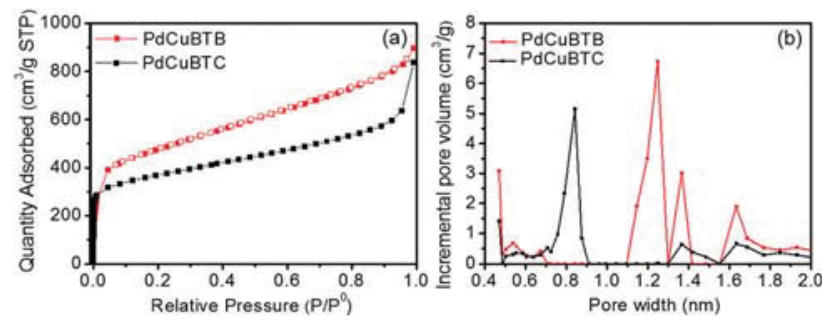

Fig. 4 (a) Ar adsorption-desorption isotherms and (b) micropore size distribution of PdCuBTC and PdCuBTB.

type I isotherms indicating the presence of well-developed micropores with the surface areas of 1175 and $1494 \mathrm{~m}^{2} \mathrm{~g}^{-1}$, respectively. Notably, we also observed the characteristics of type II isotherms at high partial pressures, which is indicative of a measurable external surface area originating from interparticle meso/macropores. In order to analyze the pore structure of MOFs, Density Functional Theory (DFT) pore size distribution analyses were conducted (Fig. 4b). While PdCuBTC revealed two peaks centered at 4 and $8 \AA$, PdCuBTB showed a peak at $4 \AA$ along with multiple peaks ranging from 11 to $17 \AA$, which are in good agreement with those of MOF- $199^{27}$ and MOF- $14 .^{28}$

In order to probe the effect of Pd OMSs on the affinity of $\mathrm{H}_{2}$ towards bimetallic MOFs, we have measured (Fig. 5a and b) $\mathrm{H}_{2}$ isotherms up to $1.3 \mathrm{bar}$ at 67,77 and $87 \mathrm{~K}^{33}$ PdCuBTC and PdCuBTB showed $\mathrm{H}_{2}$ uptake capacity of 2.6 and $2.9 \mathrm{wt} \%$, respectively at $67 \mathrm{~K}$ and decreased as the temperature increased to $87 \mathrm{~K}$. Heats of adsorption $\left(Q_{\mathrm{st}}\right)$ values for $\mathrm{H}_{2}$ were calculated from the $\mathrm{H}_{2}$ isotherms (Fig. 5c). While it is well-known that $Q_{\mathrm{st}}$ of $\mathrm{Cu}_{3} \mathrm{BTC}_{2}$ for $\mathrm{H}_{2}$ rarely decreases until the complete saturation of OMSs, ${ }^{34}$ we observed $Q_{\text {st }}$ value of 7.2 and $8.9 \mathrm{~kJ} \mathrm{~mol}^{-1}$ for PdCuBTC and PdCuBTB, respectively at zero coverage and it gradually decreased with increasing $\mathrm{H}_{2}$ loading and eventually became $\sim 5 \mathrm{~kJ} \mathrm{~mol}^{-1}$ at high loading. We suggest that the incomplete activation of PdCuBTC as evidenced from its lower $\mathrm{Cu}^{1+}$ content as well as residual coordinated $\mathrm{H}_{2} \mathrm{O}$ molecules (Fig. S7, ESI $\dagger$ ) led to lower $Q_{\mathrm{st}}$ compared to that of PdCuBTB. Enhanced $Q_{\mathrm{st}}$ values at low pressure compared to the simple $\mathrm{Cu}$ paddle wheel units in both $\mathrm{Cu}_{3} \mathrm{BTC}_{2}$ and $\mathrm{Cu}_{3} \mathrm{BTB}_{2}$ clearly demonstrate the effect of Pd OMSs on the superior $\mathrm{H}_{2}$ binding. We attribute the lower $\mathrm{H}_{2} Q_{\text {st }}$ at higher loading to the presence of meso/macropores in the MOFs. This result also matches well with the previous report by Sumby and Doonan, ${ }^{24}$ which also showed enhanced $Q_{\text {st }}$ values in the range of 8.6-10 kJ mol${ }^{-1}$ for $\mathrm{H}_{2}$ in their metal-organic polyhedras composed of $\mathrm{Pd}-\mathrm{Cu}$ paddle wheel units.

In order to elucidate the effect of the strong $\mathrm{H}_{2}$ binding at room temperature $\mathrm{H}_{2}$ storage capacity (Fig. 5a and b), we conducted $\mathrm{H}_{2}$ adsorption/desorption measurement at $298 \mathrm{~K}$, which showed irreversible chemisorption such that the adsorbed hydrogen molecules did not come back even after heating the sample to $100{ }^{\circ} \mathrm{C}$. The second $\mathrm{H}_{2}$ isotherm of PdCuBTC at $298 \mathrm{~K}$ showed almost no adsorption, confirming that the first adsorption was irreversible and collapsed sample (Fig. 5a). Importantly, TCD analysis did not show any $\mathrm{H}_{2}$ desorption, thus further proving irreversible adsorption and/or chemical reaction, that is thermally activated near room temperature. 

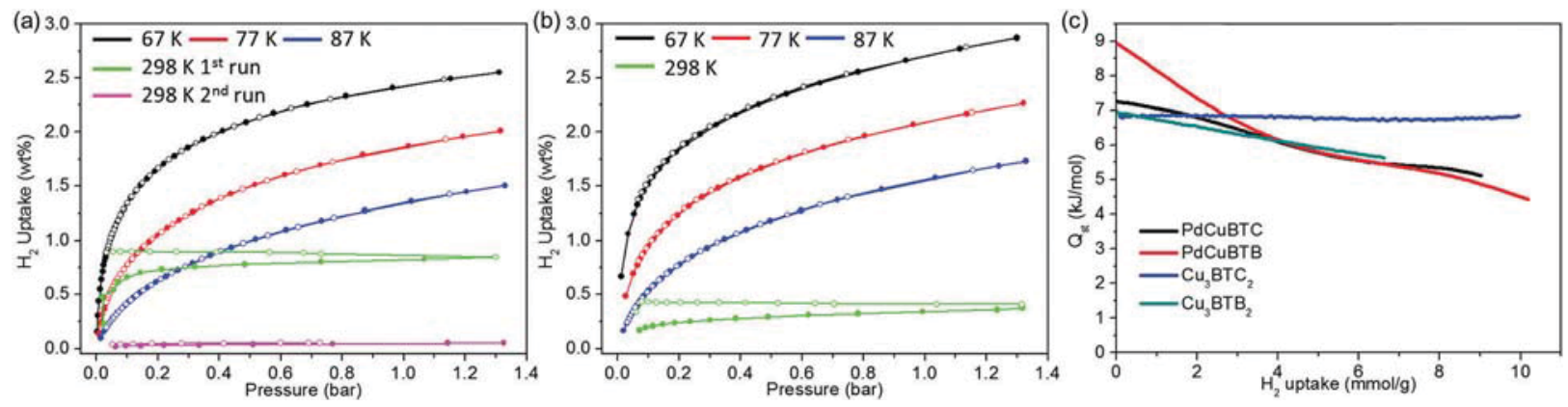

Fig. $5 \mathrm{H}_{2}$ adsorption and desorption isotherms of (a) PdCuBTC and (b) PdCuBTB at 67, 77 and $87 \mathrm{~K}$. (c) Isosteric heats of adsorption $\left(Q_{\mathrm{st}}\right)$ values of PdCuBTC and PdCuBTB for $\mathrm{H}_{2}$ as a function of its absolute loading. The $Q_{\mathrm{st}}$ values were calculated using $\mathrm{H}_{2}$ adsorption data at 67,77 and $87 \mathrm{~K}$ using the Clausius-Clapeyron equation. Blue dotted line indicates the $Q_{s t}$ of $\mathrm{H}_{2}$ for $\mathrm{Cu}_{3} \mathrm{BTC} \mathrm{C}_{2}$.

Negligible $\mathrm{N}_{2}$ adsorption of the MOFs after the $\mathrm{H}_{2}$ uptake experiment at $298 \mathrm{~K}$ points to the degradation of framework structure, which is also visually verified by the fact that the sample color turned from light green to black (Fig. S9 and S10, ESI $\dagger$ ) FT-IR spectra of PdCuBTC showed both $\left(\mathrm{COO}^{-}\right)$as and $\mathrm{C}=\mathrm{O}$ peak at 1611 and $1701 \mathrm{~cm}^{-1}$, respectively (Fig. S11, ESI $\dagger$ ), thus indicating the partial hydrogenation $\mathrm{COO}^{-}$of BTC and the reduction of Pd and resulting in the collapse of MOF structure, which might be attributed to the dissociative adsorption of $\mathrm{H}_{2}$ to the Pd OMSs facilitated by the densely located Pd/Cu paddle wheel units at $298 \mathrm{~K}$.

In conclusion, we demonstrated successful synthesis of two bimetallic, high surface area, MOF structures incorporating Pd-Cu paddle wheel units under mild reaction conditions. The analysis of Pd-Cu MOFs revealed nearly 1:1 metal ratio of $\mathrm{Pd}$ and $\mathrm{Cu}$ and their homogeneous distribution, thus inheriting the atomic-level order of predesigned Pd-Cu metal cluster. The positive effect of Pd incorporation on $\mathrm{H}_{2}$ affinity was clearly probed with increased $Q_{\mathrm{st}}$ values. In a broader context, the precise positioning of metal centers in multimetal MOFs could certainly help to fully understand the origin of gas affinity and reactivity in these systems, thus contributing to the design of new sorbents with fully controlled/understood functions.

We acknowledge the support from the Swiss National Science Foundation (SNF) for funding of this research (200021-175947).

\section{Conflicts of interest}

There are no conflicts to declare.

\section{References}

1 G. Ferey, Chem. Soc. Rev., 2008, 37, 191-214.

2 H.-C. Zhou, J. R. Long and O. Yaghi, Chem. Rev., 2012, 112, 673-674.

3 M. Eddaoudi, J. Kim, N. Rosi, D. Vodak, J. Wachter, M. O'Keeffe and O. M. Yaghi, Science, 2002, 295, 469-472.

4 P. Z. Li, X. J. Wang, S. Y. Tan, C. Y. Ang, H. Z. Chen, J. Liu, R. Q. Zou and Y. L. Zhao, Angew. Chem., Int. Ed., 2015, 54, 12748-12752.

5 A. Cadiau, K. Adil, P. M. Bhatt, Y. Belmabkhout and M. Eddaoudi, Science, 2016, 353, 137-140.

6 D. Kim and A. Coskun, Angew. Chem., Int. Ed., 2017, 56, 5071-5076.

7 J. Lee, O. K. Farha, J. Roberts, K. A. Scheidt, S. T. Nguyen and J. T. Hupp, Chem. Soc. Rev., 2009, 38, 1450-1459.

8 D. Kim, D. W. Kim, O. Buyukcakir, M.-K. Kim, K. Polychronopoulou and A. Coskun, Adv. Funct. Mater., 2017, 1700706.

9 R. J. Comito, K. J. Fritzsching, B. J. Sundell, K. Schmidt-Rohr and M. Dincă, J. Am. Chem. Soc., 2016, 138, 10232-10237.
10 C. B. He, K. D. Lu, D. M. Liu and W. B. Lin, J. Am. Chem. Soc., 2014, 136, 5181-5184.

11 K. Liang, J. J. Richardson, J. Cui, F. Caruso, C. J. Doonan and P. Falcaro, Adv. Mater., 2016, 28, 7910-7914.

12 L. E. Kreno, K. Leong, O. K. Farha, M. Allendorf, R. P. Van Duyne and J. T. Hupp, Chem. Rev., 2012, 112, 1105-1125.

13 Y. Li, S. S. Zhang and D. T. Song, Angew. Chem., Int. Ed., 2013, 52, 710-713.

14 F. Wang, W. Liu, S. J. Teat, F. Xu, H. Wang, X. Wang, L. An and J. Li, Chem. Commun., 2016, 52, 10249-10252.

$15 \mathrm{M}$. Hu, J. Reboul, S. Furukawa, L. Radhakrishnan, Y. Zhang, P. Srinivasu, H. Iwai, H. Wang, Y. Nemoto, N. Suzuki, S. Kitagawa and Y. Yamauchi, Chem. Commun., 2011, 47, 8124-8126.

16 J. Tang and Y. Yamauchi, Nat. Chem., 2016, 8, 638-639.

17 A. Dhakshinamoorthy and H. Garcia, Chem. Soc. Rev., 2012, 41, 5262-5284.

18 J. Yu, C. Mu, B. Yan, X. Qin, C. Shen, H. Xue and H. Pang, Mater. Horiz., 2017, 4, 557-569.

19 P. Falcaro, R. Ricco, A. Yazdi, I. Imaz, S. Furukawa, D. Maspoch, R. Ameloot, J. D. Evans and C. J. Doonan, Coord. Chem. Rev., 2016, 307, 237-254.

20 M. Sabo, A. Henschel, H. Froede, E. Klemm and S. Kaskel, J. Mater. Chem., 2007, 17, 3827-3832.

21 Y. E. Cheon and M. P. Suh, Angew. Chem., Int. Ed., 2009, 48, 2899-2903.

22 C. Zlotea, R. Campesi, F. Cuevas, E. Leroy, P. Dibandjo, C. Volkringer, T. Loiseau, G. Ferey and M. Latroche, J. Am. Chem. Soc., 2010, 132, 2991-2997.

23 G. Li, H. Kobayashi, J. M. Taylor, R. Ikeda, Y. Kubota, K. Kato, M. Takata, T. Yamamoto, S. Toh, S. Matsumura and H. Kitagawa, Nat. Mater., 2014, 13, 802-806.

24 J. M. Teo, C. J. Coghlan, J. D. Evans, E. Tsivion, M. Head-Gordon, C. J. Sumby and C. J. Doonan, Chem. Commun., 2016, 52, 276-279.

25 S. Wongsakulphasatch, F. Nouar, J. Rodriguez, L. Scott, C. L. Guillouzer, T. Devic, P. Horcajada, J.-M. Grenèche, P. L. Llewellyn, A. Vimont, G. Clet, M. Daturi and C. Serre, Chem. Commun., 2015, 51, 10194-10197.

26 N. S. Akhmadullina, N. V. Cherkashina, N. Y. Kozitsyna, I. P. Stolarov, E. V. Perova, A. E. Gekhman, S. E. Nefedov, M. N. Vargaftik and I. I. Moiseev, Inorg. Chim. Acta, 2009, 362, 1943-1951.

27 S. S.-Y. Chui, S. M.-F. Lo, J. P. H. Charmant, A. G. Orpen and I. D. Williams, Science, 1999, 283, 1148-1150.

28 B. Chen, M. Eddaoudi, S. T. Hyde, M. O'Keeffe and O. M. Yaghi, Science, 2001, 291, 1021-1023.

29 W. Zhang, Z. Chen, M. Al-Naji, P. Guo, S. Cwik, O. Halbherr, Y. Wang, M. Muhler, N. Wilde, R. Gläser and R. A. Fischer, Dalton Trans., 2016, 45, 14883-14887.

30 J. Szanyi, M. Daturi, G. Clet, D. R. Baer and C. H. F. Peden, Phys. Chem. Chem. Phys., 2012, 14, 4383-4390.

31 N. Nijem, H. Bluhm, M. L. Ng, M. Kunz, S. R. Leone and M. K. Gilles, Chem. Commun., 2014, 50, 10144-10147.

32 A. S. Duke, E. A. Dolgopolova, R. P. Galhenage, S. C. Ammal, A. Heyden, M. D. Smith, D. A. Chen and N. B. Shustova, J. Phys. Chem. C, 2015, 119, 27457-27466.

33 I. Eryazici, J. T. Hupp, O. K. Farha and T. Yildirim, J. Am. Chem. Soc., 2013, 135, 11887-11894.

34 H. Du, J. Bai, C. Zuo, Z. Xin and J. Hu, CrystEngComm, 2011, 13, 3314-3316. 